\title{
Learning Localization through Trans-Atlantic Collaboration: Bridging the Gap between Professions
}

\section{Tutorial}

\author{
-Feature by
}

Birthe Mousten, Bruce Maylath, Sonia Vandepitte, and John Humbley

\begin{abstract}
In light of what has taken place since their presentation at the IEEE International Professional Communication Conference in 2005, the authors describe additional requirements and merits of matching technical writing students in the US with translation students in Europe in a collaborative assignment. Where the original article dealt with how to set up and organize the collaboration, this tutorial delves into the pedagogical challenges and the process dynamics involved in such an exchange, including mediation, power, and teamwork issues.
\end{abstract}

Index Terms-Editing, exchange, localization, negotiation, power, translation standards.

C industry workplaces where the increased use of digital media for quick and efficient communication is possible. The resulting increased cooperation between multinational partners is vital for expediency and success. Email as a medium is an increasingly prevalent way of furthering collaboration, allowing the employees to create a more hands-on approach to shaping texts for users of other languages and cultures. In education, the media can be employed to set up collaborative partnerships.

Research on international collaborative projects in higher education is, however, rather scarce. When we started our project in 2000, only one article was available on a similar project: Duell and Gregory describe the two phases of the interaction between an English-language class in Tokyo International University, Japan, and a branch campus in Salem, Oregon, US, via the web [1]. Duell and Gregory's main purpose in the project was for students to learn how to use new electronic tools. In the meantime, Okubo and Kumahata have reported on their international educational collaboration between Baylor University and Tokyo Institute of Polytechnics [2]. Students taking Japanese and

Manuscript received March 05, 2009; revised July 28, 2009; accepted February 08, 2010.

B. Mousten is with the Aarhus School of Business, Aarhus University, Aarhus DK-8210, Denmark (email: bmo@asb.dk). B. Maylath is with North Dakota State University, Fargo, ND 58108-6050 USA (email: bruce.maylath@ndsu.edu).

$\mathrm{S}$. Vandepitte is with Translation Studies, University College Ghent, Ghent B-9000, Belgium (email: sonia.vandepitte@hogent. be).

J. Humbley is with Université Paris 7-Denis Diderot, Paris 75205, France (email: humbley@eila.univ-paris-diderot.fr).

IEEE 10.1109/TPC.2010.2077481 students learning English communicated with each other via web-based video and text chat sessions. The authors conclude that learning a foreign culture definitely improved with communication methods that used online technologies.

In our Trans-Atlantic Project, however, the universities are not related to each other through any formal agreements, written or otherwise. Instead, relationships are established between individual instructors. Longstanding partners include instructors at Aarhus University's School of Business (Denmark), University College Ghent (Belgium), University of Paris 7-Denis Diderot (France), and University of Wisconsin-Stout (US). New partners have joined the network, namely from the University of Trieste (Italy), North Dakota State University (US), and, for one brief year, the University of Graz (Karl-Franzens-Universität, Austria). The project's genesis, structure, and aims are enumerated in Humbley et al. [3] and vary considerably according to the wishes of the participating institutions. There and in other publications we have described the project's history and organic development as a grassroots network and delineated the project's ground rules, their practical nature, the theoretical framework behind the partnerships, and the logistics behind their operations [3]-[5].

Generally, students are expected to have already mastered the necessary computer skills and proficiency in language skills. The project differs from most other exercises in that students are put into a semi-lifelike situation: Technical students learn how to relate to prospective translators of their work, and translation students have contact with the writers of their source texts, who also act as their clients. Thus, students become aware of 
the diversity of the world community in which their technical documents travel.

In this paper, we attempt to answer the following questions:

- What potential challenges might instructors face new to these partnerships? Can baseline requirements or criteria be established to ensure that obstacles can be overcome? When a new project assignment is substituted or when a project assignment takes on a new character, what can instructors be alerted to?

- What can be learned from collaborative projects, not only by students and staff, but also by researchers engaged in writing and translation-process studies?

\section{Previous Research: Snell-Hornby, TYMOCZKO, AND GENTZLER}

According to Snell-Hornby,

The tendency towards the end of the twentieth century, and not only in Translation Studies, was clearly away from strict compartmentalization and towards interdisciplinary cooperation, away from rigid ideology and towards real-life experience. [6, p. 150]

Although some research has been carried out in this area [3], [7]-[9], a more thorough understanding of the processes involved is needed. Many analyses compare translations with the original text or intention, but the complexities and problems involved in the translation process still remain unresolved. In localization, for instance, one of the marketer's decisions is to opt for either simultaneous market access or delayed market access. The latter may involve more traditional ontogenetic work stages, whereas the decision to market in many markets simultaneously calls for completely different work processes, among them preparing documents in different languages at the same time. This challenges the concepts of source and target texts.

Tymoczko and Gentzler mention different roles assumed by different actors in different projects. Two of their points relate to our Trans-Atlantic Project in collaboration, namely, that the translator was never a neutral party in the translation process and that today's translation takes place from multicultural environment A to multicultural environment B [10, pp. 216-217]. Thus, a multitude of choices, many of them subjective (e.g., whether or not to delegate power to the target market), must be made according to company policies. An investigation of one of these companies (VELUX) concluded that

global and local forces vary from market to market, and therefore it is difficult, maybe impossible, for a company with VELUX's corporate principles to define the borderline between global and local forces, because the borderline differs with the locales in question. [11, p. 232]

\section{Collaborative Partnership Requirements}

Establishing Goals Instructors must discuss goals, some of which are shared but some of which can vary tremendously. In our Trans-Atlantic Project, this occurs during the initial stages of a project, similar to the process of creating values and visions in a company. The following issues soon emerged.

Defining Common Ground: The common denominator for all our exchanges has been raising awareness of cultural differences and inclusion of some sort of translation or "text transfer." This concept has, however, been criticized over the years [7, pp. 12-16], [12, pp. 1-6]. Since the Trans-Atlantic Project involves the travel of texts from one culture to another, we have gradually replaced the term "text transfer" with "text travel." The latter draws increased attention to the process, rather than just source and target texts. Text travel, therefore, covers diverse processes in the Trans-Atlantic Project such as texts flowing in different directions at different times, subjected to diverse cultural and linguistic changes on the way.

Involving Partners: Participants already in the network can easily take for granted problems they had when they first joined the network. Hubscher-Davidson reminds us that successful collaborative work needs to be participatory and involves all parties, and in this connection, she draws attention to the importance of detailed communication between the instructors [13, p. 87]. Along the same lines, Ramsden emphasizes cooperation in saying that teachers foster learning by listening to students and other teachers in an effort to improve teaching practices [14, pp. 113-116].

Adapting to Changes: Collaborative partnerships are not only occupied with internal organization factors; external factors may surface too, and when 


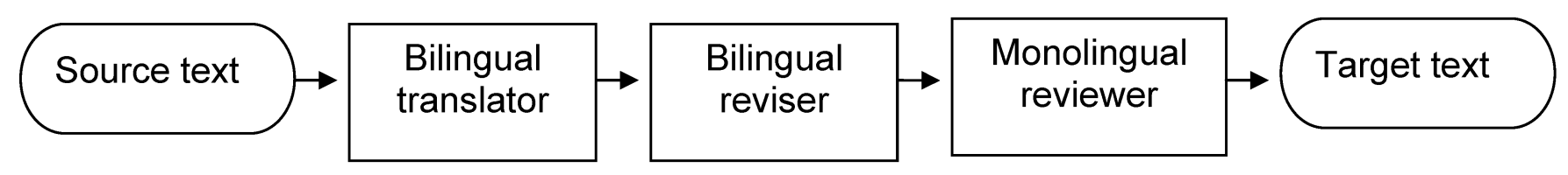

Fig. 1. Direction of text travel.

they do, they can reshape the project. This occurred in 2006 when the European Union introduced a new standard for translation, the EN15038:2006. Although this standard does not use the term "text travel," it specifies how any translation can go through obligatory and nonobligatory phases before it reaches a new audience. The obligatory phases require a qualified translator bilingual in the two languages and a reviser, different from the translator but bilingual in the same two languages. The standard also mentions a third player in the text transfer, a reviewer who need not be bilingual. Rather, the reviewer familiar with the subject matter can qualify for the job as a monolingual representative of the target culture and does not have to be a language professional [15]. For this review to be relevant, however, the reviewer must at some level be a subject matter expert or a locale expert. (See Fig. 1.)

Another example is when teachers' curricula change and new or substituted assignments require surmounting obstacles and mishaps. One of these difficulties occurred when the students at the University of Paris 7-Denis Diderot had heard lectures on the general principles of technical writing based on the genre of instructions. When topics arrived from the University of Wisconsin-Stout (UW-Stout), it became apparent that the assignment for them was not writing instructions, a relatively formalized text type, but writing a report, which is much less formal. The change in focus turned out to destabilize the French students. An unforeseen change in the writing assignment led to the translation students' not knowing exactly what was expected of them, maybe because of their limited grasp of the technical writing principles.

A related problem arose in the exchange between Belgian students at University College Ghent and US as well as the Canadian students at North Dakota State University (NDSU). In Fall 2007, it turned out that the new upper-division course Business and Professional Writing in NDSU's recently developed "vertical writing program" did not include the instruction-writing assignment. Via email, the instructors discussed other assignments that might be substituted and eventually settled on proposal texts. These included persuasive features, a prerequisite for inclusion in the course at Ghent. Although the NDSU students were urged to choose topics that could be applicable in Belgium (e.g., vaccinating cattle against anthrax, developing emergency procedures for an influenza epidemic), the proposals addressed highly specific local laws and customs. The professional writing students were not aware of the extent of local rootedness until they began comparing legislation and agency directives in their native and adjoining US states of North Dakota and Minnesota and the Canadian province of Manitoba. Through internet research, they then tried to investigate corresponding Flemish, Belgian, and European Union regulations but could find little in English, the only language in which any of them had more than a basic knowledge. Faced with more complexity than they anticipated, the NDSU students often left their texts general and did not reach the level of complexity that the Ghent students were used to. However, the students did experience a cross-cultural cooperative exercise.

\section{Organizing Cross-Professionally}

Basic Workflow Chart: Many projects have evolved from our Trans-Atlantic Project network; however, their commonalities are detailed in Mousten, Vandepitte, and Maylath [5, p. 133]. There we advocate simulating a real client for a text, according to Freinet's pedagogy [16], to allow technical writing students to learn technical writing skills in the text-production phase and translation students to learn translation, revision, editing, and adaptation skills.

With that in mind, we devised the chart in Fig. 2 for prototypical projects. As Fig. 2 shows, the initial cooperation was simply designed. The instructors at participating universities define the scope of the cooperation. The technical writing student(s) then undertake(s) the first step, writing or preparing a set of instructions. A translation student(s) then translates the text, contacting the technical writer, if necessary, to clarify points and discuss differences in languages, systems, markets, and cultural references. Most often, negotiation and 


\begin{tabular}{|l|l|}
\hline Document travel & Negotiation \\
\hline
\end{tabular}

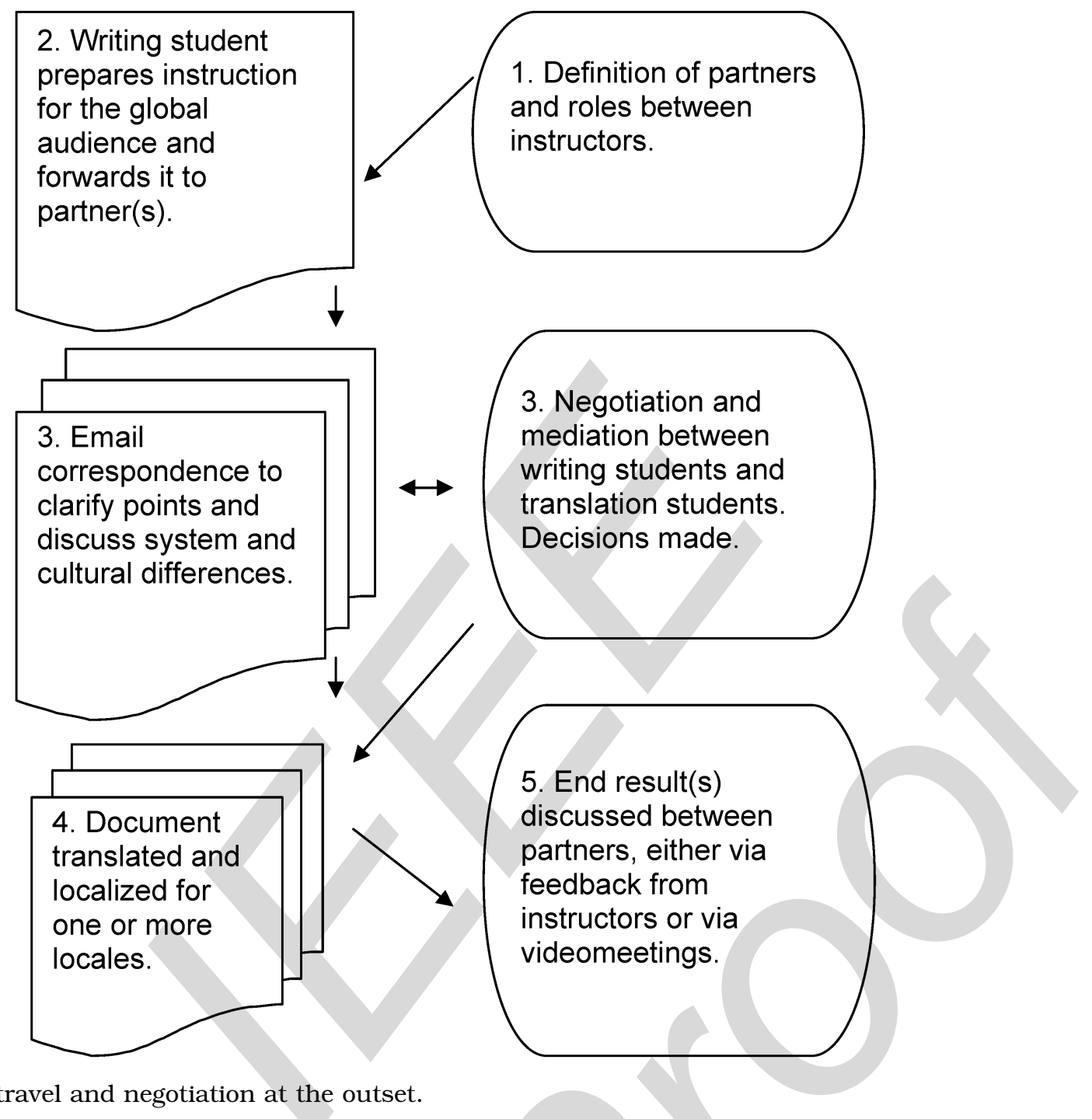

Fig. 2. Document travel and negotiation at the outset.

mediation take place via email, though sometimes a software platform such as a wiki or other website is effectively used. The translated, localized document is then returned to the writers, sometimes with comments attached about changes prompted by the need to localize.

With time, the process often becomes more complex. The participants and their roles may vary, reflecting point 2 (in Fig. 2): Sometimes text travel starts with the translators, who translate a text from their native language to the technical writing students' language for the latter to review, edit, and render idiomatic. The only constant comes at point 3 , where negotiation and mediation take place via email. At point 4, the target market may differ. At point 5-project evaluation-the ideal exchange via videoconferences has sometimes been impossible because the institutions' semesters have not aligned; however, feedback between instructors has been consistent and continual.

Finding a Window of Opportunity: The time available for collaborative projects tends to be shorter than participants anticipate. For example, in the projects conducted between Paris and Stout, the window of opportunity is fixed between October 10 and early December. Because of differing holidays, a provisional calendar should be fixed by the two instructors on a week-by-week basis. (See Table I.)

During the exercise, it is important for both parties to realize that each is complementary to the other 
TABLE I

CALENDAR OF Operations AS PlanNed FOR 2007 FOR THE FRENCH-AMERICAN PROJECT

\begin{tabular}{c|l|l}
\hline Week & \multicolumn{1}{|c}{ French students } & \multicolumn{1}{|c}{ American students } \\
\hline $\begin{array}{c}\text { Before } \\
\text { Week 1 }\end{array}$ & -- & \multicolumn{1}{|c}{$\begin{array}{l}\text { Chose topic for the writing project; post it } \\
\text { on the forum }\end{array}$} \\
\hline 1 & $\begin{array}{l}\text { Lecture on the principles of technical writing; } \\
\text { receive and choose the subject of the writing } \\
\text { project }\end{array}$ & Prepare the writing exercise \\
\hline 2 & $\begin{array}{l}\text { Research and write a first draft in French on the } \\
\text { same topic }\end{array}$ & $\begin{array}{l}\text { Send the finished writing project to the } \\
\text { French students }\end{array}$ \\
\hline 3 & $\begin{array}{l}\text { Receive the American students' texts, start to } \\
\text { translate; communicate with American students; } \\
\text { prepare the videoconference }\end{array}$ & Answer French students' questions \\
\hline 4 & Videoconference; postmortem & Videoconference; post-mortem \\
\hline 5 & $\begin{array}{l}\text { Finish translating; send comments to American } \\
\text { students }\end{array}$ & $\begin{array}{l}\text { Analyze the questions/comments/report of } \\
\text { the French students; possibly explain }\end{array}$ \\
\hline 6 & Wrap-up meeting & Wrap-up meeting \\
\hline
\end{tabular}

but that the various phases must occur in the right order. In this case, with the Americans writing the texts and the French translating them, the Americans initiated the process, their texts constituting the core exercise around which all of the rest revolved, but the French students' turn at taking initiative came soon after. The implications of this power struggle will be discussed. From a practical point of view, however, the ordering meant that any delay on the Americans' side had serious repercussions for the entire project since they were initially a step ahead. In addition, a new phase was introduced in the 2007 project, where the French students were to compose a document on the same subject as their American partner, but in French, before they received the English version for translation. In principle, this additional phase should have facilitated operations, as the Americans got two bites at the cherry: First, they chose their topic, and then they had a couple weeks to write it. The catch was that there were now two deadlines. The complementary nature of the cooperation also meant that the American students might not have focused on answering the French students' questions when posting their writing exercise.

The videoconference has been the high point of the exchange, but its timing must be carefully planned. As it almost inevitably occurs outside ordinary class times because of time zone differences, the students must know about it in advance, preferably at the beginning of the semester, so that as many students as possible can participate. But it is not enough to hope that the students will turn up on the appointed day with questions to spark enriching discussion. For that to occur, priming is necessary, especially on the translators' side. The experience of multiple videoconferences has convinced us that each class needs to discuss ahead of time what questions to ask, the answers they might expect, and how they might incorporate the answers into their work. After the videoconference, it is useful to spend half an hour analyzing what has been achieved and what has not. The end of the exchange is also a key period. In this case, since the UW-Stout students finish their semester before the Paris students do, any delay means that the French students have no one to answer their questions-if the delay is a long one-or to react to their report. The wrap-up meeting is important for the students to reflect on their achievements, and since it is the last phase, it is the one most often sacrificed.

But the end of the exchange is not the end of the project. It is up to the participating instructors to exchange notes to build on project achievements, analyze the reasons for breakdowns in communication, and prepare for the next exchange.

\section{Dealing with Differences}

Continual Awareness of Cultural Differences: By common consent, the instructors participating in the Trans-Atlantic Project have recognized that the full impact of cultural differences is not sufficiently recognized by the participating students. Part of the problem is that students do not always have a firm grasp of their own culture and are not completely prepared to approach the cultural content of their overseas counterparts. The US students are imbued with the notion of American exceptionalism 
(a trait of which their Canadian classmates are acutely aware). The consequences for collaborative projects like ours are that US students are seldom aware that significant differences between national cultures even exist and, when they discover differences (such as those in measuring volume or weight), they assume that American ways must be better. (For a description of American exceptionalism and its dangers, see Madsen [17].) In addition, young Americans' growing aversion to group responsibility has, at times, surfaced, a trait perhaps best described in Twenge, most notably in the chapter titled "An Army of One: Me" [18]. That said, one of the main goals of the Trans-Atlantic Project is to heighten students' awareness of cultural differences, starting with their own.

To illustrate, we turn to the American-French connection. To raise their consciousness, the French students are given training in technical writing and experience in actually writing documents. In addition, to prompt the French students to take more initiative, three main innovations were introduced:

(1) A quick introduction to the principles of technical writing.

(2) Obtaining the topics from the technical students in advance of the full documents' arrival and allocating these topics to the translation students on a volunteer basis. The French students researched the topics, using French-language sources supplemented by documents in English and other languages found on the web. They then wrote their own draft document in French on the same subject as their prospective American partner. As anticipated, the independently written documents gave the authors a cultural and methodological anchorage that proved useful when they tackled the American texts. The documents that the French students produced-in a very short time-were evaluated by the French teaching staff. This experience gave the French students insights into the same sort of work that their American counterparts were conducting and, at the same time, allowed them to think about their own achievements. Instead of being mesmerized by the incoming document, they were able to analyze the differences rationally and use their newly learned writing principles.

(3) A written report to their American partners that analyzed what had been achieved. Unfortunately, due to timing difficulties, the
Stout students never received this feedback, so the Paris students did not learn how their appraisal was received by their American partners. American instructors have, however, shown the reports to students in the next semesters' classes. The translation students' appraisals of their partners in America during previous semesters have helped alert the writing students to the seriousness of their role and common pitfalls.

These three innovations seemed to offer the French students a more autonomous approach to translation, thus better preparing them to handle issues that arose in the texts. The differences were most obvious in the planning of the texts' content and organization. The American students often introduced the topic with an example, often taken from personal experience, and only in the development would they deal with general issues. The French students usually started by giving an outline of the structure of their report and what the reader would find in the various sections before announcing the topic in general terms. Their examples were shorter than those in the Americans' texts, and it was quite exceptional for them to give any personal experience. The greater involvement of the American students in their topic, reflected in their use of the first person, was often toned down in the translation by using an impersonal construction to avoid the texts' reading as an egocentric monologue. From a presentation point of view, the structure of the report was clearer in the French versions, and the translators were often chagrined by what they perceived as a lack of structure by the American students.

Keeping a Balance of Power: The earliest stages of the Trans-Atlantic Project involved only an easterly direction of text travel, namely, from the US to Denmark and Belgium: American students wrote instructions for use in Denmark and in Belgium's Flanders with texts thus translated into Danish and Dutch. The cooperation later expanded to focus on different matters, such as the communication between the parties and the cultural perspectives that had to be considered. When a Danish translation class that had already had experience with the usual project was paired with the capstone class of senior technical communication majors at UW-Stout, the direction of text travel was reversed. This experience revealed a shift in power balance. Several years later, this experience reoccurred when Belgian translation classes were paired with capstone classes of English majors at NDSU. 
In contrast to their early exchanges, the students at Aarhus were asked to find a technical text in a Danish trade and industry magazine and translate it with the purpose of informing the American readers about a development in another part of the world. Interestingly, this reversal in the direction of text travel also meant a change in team members' roles, even though the participants were the same kinds of actors: American technical writers and Danish translators of technical texts. The US students had to edit a text already written and, to clarify points in the text, they had to more consciously understand the semantics and pragmatics of the text.

Although the US technical writers in the Denmark-to-US direction of text travel were still supposed to have a slight advantage when it came to knowledge of the target language (English) and knowledge of technical matters, they were presented with issues and problems for which they did not have a quick solution. In their email exchanges, they made cautious comments along the lines of "We are not very familiar with this subject, and therefore our comments must be evaluated carefully, before they are incorporated in the texts."

Our experience in the Trans-Atlantic Project has shown us that the power balance between the different actors in the text creation and translation process depends on different parameters. Who is responsible for drafting the text? Since the next person in line is supposed to work on this drafted text, a potential power struggle already lies in the sequencing. Add to this the power struggle of the mediator to adapt the text to the target audience. One way to ease potential differences between the participants is to thoroughly prepare for the project, which involves the following three points:

(1) Team members need to become better acquainted with each other. In the beginning, we simply initiated the translation process; however, we soon found that the team members spent valuable time getting to know each other and asking questions about their collaborative partners, seemingly to pave the way for fruitful cooperation but at the expense of project time. Paretti commented on this point in an article on "distributed work," where she points out that "to prepare students to collaborate on distributed teams with subject matter experts and with other professionals" is a challenge [19, p. 222]. Coupled with Dean, Osland, and Solt's study in which students identified and compared communication problems in cyberspace to on-site communication [20, pp. 222-227], this seems to be a point worth considering. If the project managers do not set aside time for team members to become acquainted, the members will delve into this matter at random.

(2) Team members perform better with a detailed translation brief. Such a brief, as we have designed it, provides team members with information about the origin and purpose of the text; reasons for certain inclusions and exclusions from the text; the context for which the text was written, including the audience and the medium; and, finally, the envisaged use in the new setting. According to Risku, this is what happens in the workplace:

Technical communicators participate in the selection of media and content, whereas translators are seen primarily as language experts responsible for the linguistic transformation of source material. [21, p. 189]

This traditional distinction of assigned roles had to be abandoned in the Trans-Atlantic Project. Even though the overall text type had been agreed on between the instructors in the US-to-Europe direction of text travel, the European translators still had to define the medium and, to some extent, the content for each text as they saw fit for the local context. However, in Europe-to-US text travel, the role of selecting the medium and content was divided among the team members with the American students at the helm because they were closest to the available choices of media.

(3) Clarify goals rather than roles. Even when team members are at ease with one another, and even when the brief specifies most points of discussion, teamwork is essential in reaching a satisfactory goal. Coppola and Elliot have identified trust as essential in virtual teams for the work to be successful [22], something we noted early on [3] when we turned to Fukuyama's work [23] during the first years of the Trans-Atlantic Project. Trust turned out to be essential in our projects, as we witnessed the team members automatically building personal relationships before actually starting the project. This added focus on trust and close relations should be seen as a logical and necessary step because there is no chance of meeting the team partners in person. Consequently, gaining knowledge depends on teamwork, trust, and personal relationships. 
Mediation as the Hub of Success: Recent discussions in process management, action research, and translation studies have included topics such as mediation and learning, as well as power and process. Seeing the web as intercultural marketing communication, Hermeking considers the translators as professionals performing the roles of culture mediators, marketing professionals, and web designers [8, p. 48]. Risku sees text production as teamwork in which each expert within an area contributes essential information, and the decision making depends on the status and power of the experts [21, p. 94]. Katan comments on the intricacies of framing text through cultural filters and says that a cultural mediator must be able to frame a particular communication within its cultural context and, in turn, disassociate from that frame to a virtual text that guides the mediator when creating a new text for a new addressee [9, pp. 324-325].

No matter which way the direction of travel goes, it is clear that mediation of the text travel and, thus, cultural travel, turns out to be the hub of success-or lack of it. It sustains a work process that is organic and subject to development. For example, in the Europe-to-US direction of text travel, a European translator-reviser team works with a reviewer team in the US. Hence, three project phases can be identified as the formal ontogenetic phases for the team, namely, translation, revision, and reviewing. The accompanying email correspondence between the team members can be considered the informal ontogenetic text phase. Below, the formal ontogenetic text stages are presented and elaborated in an example from a text on recharging batteries. In the Danish excerpt, (which is a bit sloppy as a source text and bears much English influence,) and its English translation, the numbers refer to the comments that follow.

Danish: Nogle low-cost (1) ladere terminerer (2) ladningen ved måling af absolut temperatur (3)—en simpel men ikke særlig (4) nøjagtig metode. (5)

English: Some low cost (6) chargers terminate charging by measuring the absolute temperature-a simple but imprecise method. (4) $+(5)$

(1) The term "low-cost" has been borrowed directly from English; the normal Danish word would have been "billig" (cheap/inexpensive).
(2) The term "terminerer" (terminate) was borrowed via English from Latin and may be used in the language for specific purposes (LSP) register for this language domain. However, the conventional Danish word would be "afbryde" (cut off).

(3) Another LSP concept in this context is "absolut temperatur" (absolute temperature), which may remind the lay reader of the concept of "absolut nulpunkt" (absolute zero). However, "absolute temperature" is not normally recognizable to the reader. Although the synonym "termodynamisk temperatur" (thermodynamic temperature) is also an LSP term, it helps readers retrieve notions of heat/cold and changeable conditions.

(4) The precaution, however, taking the form of a negation ("ikke særlig" = not particularly) was omitted from the text. As a result, the hedging in the statement was removed from the translated/revised version.

(5) The Danish phrase "men ikke særlig nøjagtig metode" (but not particularly precise method) was rendered in English as the stronger and clearer phrase "but imprecise," which is the only semantic difference between the source and target texts. The change takes the form of a negation, going from an adverb (ikke = not) to a prefix (im-).

(6) One small change, important in English, is the deletion of the hyphen between "low" and "cost." Its elimination transforms the compound adjective into two separate adjectives. According to most British and American style guides, this omission is a mistake.

The native-speaker review group changed the text as follows:

Some low-cost chargers quit (7) charging a battery (8) by measuring the absolute temperature of the battery, (9)-simple but imprecise method of determining the amount of energy in the battery (10).

They made four changes:

(7) They replaced the term "terminate" with "quit." In doing so, they replaced an LSP term with an ordinary word, adding a touch of the colloquial to the text.

(8) They made explicit that the activity of charging involved a battery and, thus, clarified the statement ("charging" became "charging a battery"). 
(9) They inadvertently introduced a grammatical mistake by leaving out the indefinite article "a" in front of "simple."

(10) They also elaborated on the method ("imprecise method" became "imprecise method of determining the amount of energy in the battery").

The aforementioned translation, revision, and review stages for just one sentence included (1) problems with the use of loan words in the source texts; (2) change from LSP and, thus, field-specific register, to language for general purposes (LGP) and, thus, a common register; (3) problems in dealing with field-specific register; (4) cultural modes of expressing negatives; (5) removal of hedging; (6) deviation from writing rules; (7) formal versus informal style; (8) explication; (9) grammar; (10) inadvertent deletion; and (11) addition. To summarize, it is not surprising that discussion about the formulation and translation of a text can be a nerve wracking experience.

As for the informal ontogenetic stages, which involve negotiation and mediation, it is noteworthy that they were absent for this example. The translator/reviser group members accepted most changes but rejected the edited parts where semantic changes occurred. They returned another version in which they explained why they rejected some of the changes.

Cross-Cultural and Cross-Professional Research: If international collaboration is introduced at the master's degree level (as is the case at Aarhus School of Business/Aarhus University), it may serve as the subject of student research projects, such as a thesis. For instance, one Danish master's candidate compiled a corpus of the exchanges involved in the Trans-Atlantic Project and analyzed the cultural differences in email communication between US and Danish students. She found that the differences were minute, and a significant difference occurred in only one parameter: It was more important to the Americans to be competitive; among the Danes, it was more important to be cooperative [24, p. 77].

Researchers will also find that collaboration is fruitful ground for investigating cross-cultural and cross-professional aspects. On the relationships between source text/source culture and target text/target culture, Reiss and Vermeer's Skopos Theory [25] has gained ground along with Sperber and Wilson's Relevance Theory [26], applied in particular to translation by Gutt [27]. This, in turn, implies that the responsibility of shaping the text during text travel must, in general, be assumed by all actors in the team rather than by the sender alone. The situation corresponds to a music composer writing the notes but the performance being shaped by the musicians.

What the Trans-Atlantic Project has taught us is that obtaining good results inevitably calls for strong team member participation and productive dialog. In turn, the dialog brings virtual team members closer to one another, while the focus on different educational backgrounds fades slightly. This does not mean that problems do not arise. On the contrary, the results of collaboration have varied with the people involved. The organic development of teamwork has depended on successful collaboration within the team. The quality of the resulting texts reflects the same phenomenon. Some changed texts have come across very successfully; others have been changed in ways that made the texts illogical or introduced new errors. In general, the better the cooperation, negotiation, and mediation, the better the results.

\section{Redefining Common Ground}

It is difficult to imagine future translation studies without process studies. Likewise, it is difficult to imagine technical information travel without translation being involved. Moreover, the increased complexity of structures in translation and technology makes it hard to imagine either without effective team collaboration. Therefore, we see a new organizational setup that is already used in trade and industry. Theoretically, and in our teaching of technical writers and technical translators, we face the challenge of preparing students for this kind of collaboration.

The above assumptions call for the role of the translator to change from being a loyal translator to being a critical filterer and a more independent actor in the process of converting source text into target text. This role transition calls for collaboration with other professions and understanding and inclusion of cultural differences.

For translators, this is acknowledged in Cronin's stance that

translators are first and foremost mediators. They are the medium by which texts from one culture and language are transmitted to another. Translation is a subset of the larger sets of transmission and mediation. In this respect translation has similarities to other 
forms of mediation and transmission in our society. [28, p. 90]

To perform this act of mediation in relation to a new locale, the translator and other actors are central. The examples in this paper demonstrate that the mediation skills needed in a translation process are no less vital today than previously.

Translation studies have dealt with this issue, too, and as the cultural turn in translation has become the power turn [27]-[29], "with questions of power brought to the fore in discussions of both translation history and strategies for translation" [10, p. xvi], our recognition of the power turn becomes essential in defining contemporary problems and processes in virtual networks.

The overall question is whether universities prepare students of technical writing and technical translation for this challenge. The translation brief has forced the parties to define roles, means, and ends more specifically, but the brief has shown that the reader profile for the actual text in the new locale is sometimes unclear and not sufficiently defined in the discussion of the brief. Even if a text has been prepared for a certain newspaper, this does not equate to defining one or more reader groups, let alone writing precisely for them.

In relation to the way translation has been perceived and taught for a long time, the EU standard raises new questions and issues in translation studies, rhetorical studies, and process studies. We have to prepare students for jobs that encompass knowledge workers from different fields. The Trans-Atlantic Project is an attempt to clarify the role of the translator as the mediator of knowledge. In our earliest publication [3], we wrote that the project's results offer evidence that Rothkegel's query remains perhaps the most relevant and pressing question in global technical discourse:
How does one get across in the translated message something which is different in L1 and L2, not simply because the languages are different, but because in the two languages' cultures, the conventions on how something is communicated are not the same? [30, p. 189]

We add another question: How do we bridge the gap between the different professions, where process in the virtual team is decisive for usability and successful communication? Usability is often considered in terms of the source text but not the target text, though it is equally important there. Some student translators tried running usability tests for the texts that they translated but sometimes encountered a problem familiar in industry: If the process or procedure is place-bound, as it has been in student-produced instructions for cleaning a local swimming hall, inserting a roof window, or changing tires on a specific brand and model of motorcycle, the means for usability testing are simply not at hand. For this reason, the translator often has to resort to a mental usability test [5, pp. 134-140].

Beerli, Falk, and Diemers sum up the gap between different professions neatly:

There are many cultural factors that influence knowledge transfer, including lack of trust, differences in cultural backgrounds, perceived loss of status and rewards, lack of time and conducive meeting places, and intolerances for mistakes. [31, p. 10]

It seems that our Trans-Atlantic Project touched upon practical and theoretical issues that have included all of the points in Beerli et al.'s statement. Therefore, some measure of success must be acknowledged, although some issues probably still need to be addressed. Prime among these are the informal ontogenetic stages essential to group decision making.

\section{REFERENCES}

[1] B. Duell and W. Gregory, "Hands across the water: A pan-Pacific collaborative English language teaching project,” J. Tokyo Int. Univ., School Bus. Commerce, vol. 56, pp. 120-137, 1997.

[2] M. Okubo and H. Kumahata, "Collaborative cultural studies over the Internet: Learning cultures with virtual partners. A project between Baylor University and Tokyo University of Polytechnics," in Proc. Annu. Nat. Convention Assoc. Educational Communications and Technology, 2001, pp. 18-23.

[3] J. Humbley, B. Maylath, B. Mousten, S. Vandepitte, and L. Veisblat, "Learning localization through trans-Atlantic collaboration," in Proc. IEEE Int. Professional Communication Conf., 2005, pp. 578-595.

[4] B. Maylath, S. Vandepitte, and B. Mousten, "Growing grassroots partnerships: Trans-Atlantic collaboration between American instructors and students of technical writing and European instructors and students of translation," in Designing Global Learning Environments: Visionary Partnerships, Policies, and Pedagogies, D. Starke-Meyerring and M. Wilson, Eds. Rotterdam, The Netherlands: Sense Publishers, 2008, pp. 52-66. 
[5] B. Mousten, S. Vandepitte, and B. Maylath, "Intercultural collaboration in the Trans-Atlantic Project: Pedagogical theories and practices in teaching procedural instructions across cultural contexts," in Designing Global Learning Environments: Visionary Partnerships, Policies, and Pedagogies, D. Starke-Meyerring and M. Wilson, Eds. Rotterdam, The Netherlands: Sense Publishers, 2008, pp. 129-144.

[6] M. Snell-Hornby, The Turns of Translation Studies. Amsterdam, The Netherlands: John Benjamins, 2006.

[7] A. Pym, The Moving Text: Localization, Translation, and Distribution. Amsterdam, The Netherlands: John Benjamins, 2004.

[8] M. Hermeking, "Lokalisierung von Webseiten: Interkulturelle marketing-kommunikation,” MDÜ, vol. 55, no. 3, pp. 48-53, 2008.

[9] D. Katan, Translating Cultures: An Introduction for Translators, Interpreters and Mediators. Northampton, MA: St. Jerome Publishing, 2004.

[10] M. Tymoczko and E. Gentzler, Translation and Power. Amherst, MA: Univ. of Massachusetts Press, 2002.

[11] B. Mousten, "Globalisation and localization influences on web site text distribution: A case study of text travel between two VELUX web sites," Ph.D. dissertation, Københavns Universitet, Copenhagen, Denmark, 2008.

[12] S. Susam-Sarajeva, Theories on the Move: Translation's Role in the Travels of Literary Theories. Amsterdam, The Netherlands: Rodopi, 2006.

[13] S. Hubscher-Davidson, "A reflection on action research processes in translator training," The Interpreter and Translation Trainer, vol. 2, no. 1, pp. 75-92, 2008.

[14] P. Ramsden, Learning to Teach in Higher Education. London, UK: Routledge, 1992, pp. 113-116.

[15] European Union, Eur. Std. EN 15038, 2006.

[16] C. Freinet, Les CEuvres Pédagogiques. vols. 1-2. Paris, France: Seuil, 1994.

[17] D. Madsen, American Exceptionalism. Edinburgh, UK: Edinburgh Univ. Press, 1998.

[18] J. Twenge, Generation Me: Why Today's Young Americans are More Confident, Assertive, Entitled-and More Miserable Than Ever Before. New York: Free Press, 2006.

[19] M. C. Paretti, "Work in progress: Using e-portfolios to capture both process and product for assessing communication skills," presented at the IEEE/ASEE Frontiers in Education Conf., Savannah, GA, 2004.

[20] B. Dean, V. Osland, and M. Solt, "Lessons learned in the implementation of e-teams," Int. J. Eng. Educ., vol. 21, no. 2, 2005.

[21] H. Risku, Translationsmanagement: Interkulturelle fachkommunikation im informationszeitalter. Tübingen: Gunter Narr Verlag, 2004.

[22] N. Coppola and N. Elliot, "Big science or bricolage: An alternative model for research in technical communication," IEEE Trans. Prof. Commun., vol. 48, no. 3, pp. 261-268, Sep., 2005.

[23] F. Fukuyama, Trust. New York: The Free Press, 1995.

[24] E. Sehested, "Kulturelle dimensioner i email-korrespondancer," M.Sc. dissertation, Aarhus School of Business, Aarhus, Denmark, 2006.

[25] K. Reiss and H. J. Vermeer, Grundlegung einer Allgemeinen Translationstheorie. Tübingen: Niemeyer, 1984.

[26] D. Sperber and D. Wilson, Relevance: Communication and Cognition. Oxford, UK: Blackwell, 1986.

[27] E. Gutt, Translation and Relevance: Cognition and Context. Manchester, UK: St. Jerome, 2000.

[28] M. Cronin, “Thou shalt be one with the birds': Translation, connexity and the New Global Order," Lang. Intercult. Commun., vol. 2, no. 2, pp. 86-95, 2002.

[29] M. Snell-Hornby, "Communicating in the global village: On language, translation and cultural identity," Current Issues Lang. Soc., vol. 6, no. 2, pp. 103-120, 1999.

[30] A. Rothkegel, "Transfer of knowledge in cross-cultural discourse," in Language, Text and Knowledge: Mental Models of Expert Communication, L. Lundquist and R. J. Jarvells, Eds. Berlin, Germany: Mouton de Gruyter, 2000, pp. 189-206.

[31] A. Beerli, S. Falk, and D. Diemers, Eds., Knowledge Management and Networked Environments. New York: AMACOM, 2003.

Birthe Mousten lectures at the Aarhus School of Business, Aarhus University, Aarhus, Denmark. She teaches courses in English for science and technology and web-related text production. Her recent research comprises her Ph.D. dissertation from the University of Copenhagen, Copenhagen, Denmark, "Globalisation and localization influences on web site text distribution-A case study of text travel between two VELUX web sites," as well as two coauthored chapters in Starke-Meyerring and Wilson's Designing Globally Networked Learning Environments-Visionary Partnerships, Policies, and Pedagogies.

Bruce Maylath is a professor of English at North Dakota State University, Fargo, where he teaches courses in professional communication and linguistics. His current research focuses on translation issues in technical communication. His best-known book chapters appear in Carolyn Rude's Technical Editing (4th ed.) and Deborah S. Bosley's Global Contexts: Case Studies in International Technical Communication.
Sonia Vandepitte is a lecturer of English. She teaches English grammar and translation from and into English, coaches student translation businesses, and coordinates research activities. She has published on intonation, causal expressions, knowledge retrieval, methodological issues in translation studies, translation competencies, anticipation in interpreting, and international teaching projects. She supervises projects on parallel and comparable corpora and electronic feedback in ESL learning.

John Humbley is a professor of applied linguistics and terminology in the Department for Intercultural Studies and Applied Languages (EILA) at Université Paris 7-Denis Diderot, Paris, France, where he is in charge of the master's degree program. He has published in the field of terminology, lexicology, and translation studies, and has participated in several dictionaries. 